\title{
APLICABILIDAD DEL DERECHO PROCESAL INTERAMERICANO A UN PAIS EN TRANSICIÓN DE PAZ ${ }^{148}$
}

The applicability of inter-American procedural law to a country in peace transition

Fecha de recepción: 12 de abril de 2018

Fecha de aceptación: 25 de mayo de 2018

Dudley Duque Sierra $^{149}$

Luis Alberto Rivas Mosquera ${ }^{150}$, Andrés Francisco Mena Romaña ${ }^{151}$,

SUMARIO. Resumen, introducción, derecho procesal constitucional, codificación procesal, diálogo jurisprudencial, necesidad de aplicabilidad de estándares procesales claros, excepciones preliminares un espejismo de derecho a la defensa, conclusiones, bibliografía.

\footnotetext{
148 Tema de investigación del Semillero de Justicia Constitucional, base para la presentación de la Ponencia en el IX concurso Internacional Junior de Derecho Procesal Constitucional, celebrado en Bogotá en mayo de 2018.

${ }^{149}$ Administrador Público y Abogado, Especialista en Derecho Público de la Universidad Externado de Colombia, Magister en Derecho Procesal Constitucional de la Universidad Nacional de Lomas de Zamora de Argentina, doctorando de la misma Alma Mater, Docente Universitario y Coordinador del semillero "Justicia Constitucional" de la Facultad de Derecho y Ciencias Políticas de la Universidad Tecnológica del Chocó "Diego Luis Córdoba”. Correo electrónico: duquesd@hotmail.com, ORCID: org/0000-0001-5226-9501

150 Estudiante del décimo semestre de Derecho en la Universidad Tecnológica del Chocó "Diego Luis Córdoba", integrante del Semillero Justicia Constitucional de la facultad de Derecho y Ciencias Políticas. https://orcid.org/0000-0002-9558-9895. Correo electrónico: yumil-makial@hotmail.es

151 Estudiante del décimo semestre de Derecho en la Universidad Tecnológica del Chocó "Diego Luis Córdoba", integrante del Semillero Justicia Constitucional de la facultad de Derecho y Ciencias Políticas. Correo electrónico: luzemeris09@gmail.com
} 
Dudley Duque Sierra, Luis Alberto Rivas Mosquera, Andrés Francisco Mena Romaña

\section{COMO SE CITA ESTE ARTíCULO (APA 6)}

Duque Sierra, Dudley, Rivas Mosquera, Luis Alberto \& Mena Romaña, Andrés Francisco (2018). Aplicabilidad del derecho procesal interamericano a un país en transición de paz. Revista Jurídica Mario Alario D’Filippo, Vol. X, №. 20, pág. 213 - 226

\section{RESUMEN}

El derecho evoluciona a la par con la sociedad, principio universal de justica; los gobiernos adoptan sistemas y prácticas de aplicación del derecho, como lo hace la justicia interamericana que vela para que se aplique en lo regional lo pactado, en especial la protección y promoción de $\mathrm{DDHH}$; la norma de derecho sustancial para su efectividad requiere de un mecanismo que pueda lograr desentrañar el espíritu de las mismas permitiendo así que todas sus prerrogativas puedan ser materializadas garantizando justicia, verdad, reparación y no repetición.

La investigación se realizó utilizando el método deductivo directo; se partió conocimiento lato de la normativa existente y su contraste con el sistema internacional definido para la garantía y protección de los Derechos Humanos.

\section{Palabras Claves}

Derecho Procesal Constitucional, Ordenamiento Jurídico Interno, Discusión jurisprudencial, Espejismo judicial.

\section{ABSTRACT.}

The law evolves on par with society, the universal principle of justice; governments adopt systems and practices for the application of the law, as does interagency justice that ensures that the agreement is applied in the region, especially the protection and promotion of human rights; The norm of substantial right for its effectiveness requires a mechanism that can manage to unravel the spirit of the same allowing all their prerogatives can be materialized guaranteeing justice, truth, reparation and not repetition.

The research was conducted using the direct deductive method; it was based on the full knowledge of the existing regulations and their contrast with the international system defined for the guarantee and protection of Human Rights.

\section{Key Words}

Constitutional Procedural Law, Internal Juridical Regulation, Jurisprudential Discussion, Judicial Mirage 


\section{INTRODUCCION.}

Los fenómenos sociales de la época han obligado a que en la actualidad del mundo jurídico internacional, los sistemas hayan adoptado mecanismos que no deben pasar desapercibidos en nuestro proceso de construcción normativo debido a la gran labor institucional que trae consigo la interpretación de las normas que van en dirección a establecer pautas de efectividad y eficacia en justicia de derechos humanos que deben ir más allá del hecho concreto de tenerlos como tal; en este caso, haciendo alusión al tema que nos compete, los derechos humanos y sus espacios de resolución y competencia, entendiendo las ciencias jurídicas desde la universalidad de definiciones conceptuales que la integran, podemos decir entonces, que el derecho debe ser entendido como un conjunto de normas que regulan el desarrollo de una sociedad, en el que es imposible negar u ocultar la relación tan íntimas que esta ciencia guarda con la moral tal como lo define el lus filosofo Ronald Dworkin (Prieto, s.f. p. 354); donde quizás el derecho mirado desde otra dimensión, u otra perspectiva ofrece la idea de actuar correctamente dentro del conglomerado social que antes mencionamos.

Entendiendo entonces que el derecho como ciencia va más allá de la construcción de un sistema de normas, entiende y acepta la necesidad de que el traductor de las prerrogativas, valore los principios morales que inspiraron o en los que se fundó la construcción de la norma; dentro de este universo argumental encontramos a uno de los más grandes exponentes de la teoría jurídica, el positivista Hans Kelsen que en su obra Teoría Pura del Derecho manifestó que el jurista que estudia normas del derecho positivo y las considera válidas, debe separarse de la moral siempre y cuando esta choque con dichas normas (Kelsen, 2009, p. 162), invitaba de manera tajante a que el sistema jurídico nacional fuera el preestablecido y que el derecho internacional se integrara a éste, y dentro de lo que nos corresponde podemos afirmar que son ideas que difieren demasiado.

No obstante en la actualidad se hace necesario que sean utilizadas bajo los criterios como el "pro persona" por los agentes estatales, debido a que cada caso en particular puede señalar un escenario totalmente distinto que nos puede obligar a aplicar la norma como lo establece el ordenamiento jurídico interno, o aplicar normas de carácter internacional que ocupan determinado espacio en cada legislación estatal que pueden estas o no alejarse de la moral como un criterio auxiliar en el que se cimentó la norma; lo cierto es que hoy existe un excesivamente robustecido cuerpo normativo que asegura una protección positiva a las personas en sus derechos humanos; dichas disposiciones se encuentran sujetas a la jurisdicción de cada Estado, aún con este panorama en el plano comúnmente regional no se ha logrado avanzar en otorgar la vinculatoriedad deseada a los distintos cuerpos normativos integradores del sistema interamericano de derechos humanos; en este mismo panorama jurídico no se ha determinado de manera clara el aspecto procedimental o procesal para la reclamación y materialización efectiva de dichos derechos, para poder entonces consolidar en este Continente, dentro del 
cuadro de las instituciones democráticas, un régimen de libertad personal y de justicia social, fundado en el respeto de los derechos esenciales del hombre (Convención americana, 1969).

Debido al valor y contenido de que reviste la idea, creemos que la rama del derecho que debe asumir este rol protagónico y lograr concretar esta propuesta, es la del derecho constitucional, es por ello que en los últimos años resulta habitual escuchar acerca de una corriente doctrinaria denominada neoconstitucionalismo que tiene su origen y desarrollo en el marco de la tradición constitucional europea de los últimos 50 años (Alfonso, 2008, p. 3), mostrando notables avances en relación a la protección de los derechos de las personas. Vale la pena señalar que el neoconstitucionalismo como proceso histórico se inicia con la profunda transformación de los ordenamientos jurídicos europeos con la expedición de las constituciones luego de la Segunda Guerra Mundial y la tarea que, a partir de ellas, comienzan a desarrollar los tribunales constitucionales de los países del viejo mundo. Estas transformaciones son claramente perceptibles, a partir de la promulgación de las constituciones de la posguerra, en países como Alemania, Italia y Francia y, más tardíamente a partir de 1978, España. Que da nacimiento a una nueva fase en el marco del proceso histórico del constitucionalismo europeo que tuvo comienzo a finales del siglo XVIII, con características propias y diferenciales respecto a las etapas anteriores; de ahí el nombre de neoconstitucionalismo. Algunas de estas transformaciones estructurales del sistema jurídico se expanden luego, especialmente a partir de la década del 90, hacia América Latina (por ejemplo, a Colombia, con la constitución de 1991 y la, a veces sorprendente, jurisprudencia de su tribunal constitucional), los ex países comunistas (por ejemplo, Hungría) y otros estados como Sudáfrica, India y Turquía, por la importancia que van adquiriendo dentro de ellos la Constitución como norma y disposición jurídica, y los tribunales constitucionales como órganos que velan por asegurar su supremacía, especialmente mediante la tutela y el desarrollo de los derechos humanos por parte de los jueces constitucionales (Alfonso, 2008, Pp. 5-6).

Problema de investigación: ¿Cómo lograr una efectiva aplicabilidad del Derecho Procesal Interamericano a un País en transición de paz, tendiente a la protección de los Derechos Humanos reconocidos?

\section{2- Derecho procesal constitucional.}

En este estadio existencial del derecho constitucional contemporáneo es menester precisar el derecho procesal constitucional que como especialidad del derecho constitucional obra tendiente a garantizar la tutela efectiva de los derechos constitucionales, integrándose no sólo por leyes positivas, sino también por la costumbre jurídica (derecho consuetudinario), usos, costumbres y convenciones. Por ello, enfrentarnos a una disciplina como ésta, implica, muchas veces, la necesidad de internarnos en una maraña normativa, que dificulta el estudio y la práctica de esta materia fundamental para el respeto de la Constitución y el Estado de Derecho (Sagües, s.f. p.1), 
en ese sentido es indudable la importancia que ha tenido el derecho procesal constitucional en la efectiva aplicación del derecho desde mediados del siglo xx.

Indiscutiblemente la norma de derecho sustancial para su efectividad requiere de un mecanismo por excelencia que pueda lograr desentrañar el espíritu de las mismas permitiendo así que todas sus prerrogativas puedan ser materializadas garantizando justicia y verdad a los sujetos de un determinado estado. Para ello se ha constituido el derecho procesal constitucional, (Campbell,2002, p. 137), desde el punto de vista doctrinal el origen del concepto del derecho procesal constitucional fue creado por Hans Kelsen; Alcala-zamora; Alcalamandrei y cappelletti pero sin lugar a dudas uno de sus mayores exponentes en la edad contemporánea en el continente americano fue Héctor fix- Zamudio, quien le da forma y conceptualiza de manera puntual qué es el derecho procesal constitucional, tal como lo establece Eduardo Ferrer- MacGregor (Ferrer Mac-Gregor, 2008 pp. 589 y 599); cabe la pena indicar, que la ciencia procesal constitucional se explica a partir de la relación que existe entre el proceso y la Constitución; vale decir, como se aplican las garantías judiciales de la norma fundamental en los procesos entre partes. En este, el rol protagónico que han jugado las constituciones dentro de los Estados americanos contemporáneos, como es el caso de Colombia testigo del avance del derecho constitucional plasmado de la Constitución de 1991, Carta que establece una relación a la materia constituida en la supra legalidad de la Constitución tal como lo establece el artículo 4ํ de la Constitución colombiana (Constitución Política de Colombia, Art. 4ํ)).

Según Tirado y Luna (2015, p. 25) podemos concluir que el derecho procesal constitucional es el conjunto de instituciones creadas por el intérprete de la constitución para ejecutar los derechos consagrados en ésta.

\section{3- Codificación procesal}

Es imposible concebir un Estado sin la orientación normativa de una Constitución que determine de manera clara la organización de la sociedad estipulando dentro de ella las obligaciones, garantías y libertades de los ciudadanos sujetos a la jurisdicción de un ente estatal, así como también las instituciones encargadas de velar por la efectivización de esos preceptos constitucionales, de igual forma es fundamental mencionar que a lo largo de la historia muchos Estados han logrado alcanzar una materialización constitucional sin la existencia de una codificación procesal especialmente positivada en sus ordenamientos jurídicos tal como sucede con Colombia, Brasil, México, Guatemala, costa rica y ecuador, sin embargo estos estados cuentan con una legislación dispersa en la materia que de alguna forma regulan los procedimientos en esta área del derecho, pero el derecho procesal constitucional debe unir fuerzas para la construcción de un estatuto de carácter supranacional que pueda lograr recoger los parámetro en materia procesal que existen dentro de los sistema jurídicos internacionales, 
que se conviertan en las reglas de juego claras precisas y concretas que se aseguren el acceso a la justicia internacional.

En ese sentido de conformidad con lo anterior existen tres escenarios de categorización de los Estados, de acuerdo a las experiencias latinoamericanas entorno a la materia procesal constitucional y su desarrollo, entre las que encontramos (Corrado de Paz, s.f. pp. 284- 287):

1- Aquellas donde se encuentra un cuerpo normativo que adoptado el nomen iuris código procesal constitucional: Son aquellos Estados donde se determinó a través de un código procesal la regulación del derecho procesal constitucional estableciendo, las reglas, pautas, parámetros que deben orientar la materia, entre los países abantes en esta iniciativa encontramos a Perú, Bolivia y a la provincia de Tucumán en Argentina, si bien son avances destacados también es cierto que dicha idea, propuesta se ha quedado rezagada ante el gran auge de la rama constitucional en el continente.

2- Aquellos que cuentan con legislación especializada pero que no han adoptado el nomen iuris de código procesal constitucional: es decir que existe una ley que regula los procesos constitucionales, pero esta normatividad no posee el carácter de código procesal constitucional, pero cuenta con un desarrollo normativo que permite establecer el trámite de dichas acciones constitucionales dentro de esta categoría encontramos a los estados de Guatemala, Costa Rica, Provincia entre Rio(Argentina) y Ecuador.

Y por último encontramos aquellos Estados que cuentan con una legislación dispersa en la materia constitucional entre los que se encuentra México, Brasil y Colombia, estas últimas categorías fueron abordadas anteriormente, reconociendo como primero que estos Estados han tenido la voluntad de intentar establecer así fuese de manera somera unas pautas que aseguren una autonomía de la rama constitucional, pero sobre todo la idea final de construir un código procesal, es por ello que el presente trabajo investigativo tiene por objeto recopilar del sistema interamericano las reglas procedimentales que aseguren a los sujetos en controversia, el desarrollo de un debido proceso legal que no viole las garantías procesales, la igualdad de armas, derecho de contradicción.

\section{4- Dialogo jurisprudencial.}

Uno de los principales fundamentos en los cuales se cimenta esta propuesta investigativa radica en la necesidad de garantizar una real eficacia en la promoción y protección de los derechos fundamentales de las personas, permitiendo que estas puedan tener la posibilidad a un acceso a la justicia y a la tutela efectiva de sus derechos desde el punto de vista convencional. Además de lo imperioso que resulta para el sistema Convencional, establecer bases sólidas en torno a la seguridad jurídica que debe existir alrededor de los procedimientos que se adelantara ante la 
justicia Interamericana de Derechos Humanos, y por ende en las regulaciones de los distintos Estados convencionalizados contengan unos mecanismos que garanticen el acceso a la tutela judicial efectiva y el acceso al sistema y las ritualidades que se adelantan dentro del mismo.

El concepto de "diálogo jurisprudencial" tal y como se caracteriza, como lo menciona Mac-Gregor \& García (2013) "implica una interlocución mediante resoluciones, pronunciamientos y criterios jurisdiccionales, evidentemente producida por tribunales dialogantes" (p. 15). No obstante, para el correcto desarrollo efectivo de tal fenómeno, habría que agregar una idea más concisa del diálogo, el cuál hoy tiene cabida en materia de tutela de derechos, tomando en consideración, dialogo entre tribunales, Originando así, nuevas perspectivas sobre el papel de los tribunales en los estados convencionalizados para el correcto manejo y protección de los derecho que son directamente atribuidos por la Constitución como "patrimonio jurídico" de sus titulares, independientemente de la ley (Zagrebesky, p.199).

No podemos dejar de mencionar el lugar que ocupa las interacciones jurídicas internacionales dentro de los ordenamientos jurídicos de los estados es por ello que se crean herramientas jurídicas tendentes a asegurar el efectivo cumplimiento de las disposiciones internacionales, dentro de esas categorías encontramos el "EL Bloque de Constitucionalidad" que tiene su origen en Francia como resultado de la decisión del consejo constitucional francés que estableció que si bien en los 92 artículos de la constitución no se autorizaba una remisión a una norma distinta, el preámbulo abría la puerta a la aplicación de declaraciones que no estaban contempladas en este cuerpo normativo, (Rubio \& Daranas, 1997, p. 233) en América latina el bloque de constitucionalidad es considerada como una figura naciente, sin embargo esta surge de manera particular en nuestro país con la creación de la constitución política de 1991 (Constitución Política de Colombia Art.93): "Los tratados y convenios internacionales ratificados por el Congreso, que reconocen los derechos humanos y que prohíben su limitación en los estados de excepción, prevalecen en el orden interno. Los derechos y deberes consagrados en esta Carta, se interpretarán de conformidad con los tratados internacionales sobre derechos humanos ratificados por Colombia. El Estado Colombiano puede reconocer la jurisdicción de la Corte Penal Internacional en los términos previstos en el Estatuto de Roma adoptado el 17 de julio de 1998 por la Conferencia de Plenipotenciarios de las Naciones Unidas y, consecuentemente, ratificar este tratado de conformidad con el procedimiento establecido en esta Constitución". La admisión de un tratamiento diferente en materias sustanciales por parte del Estatuto de Roma con respecto a las garantías contenidas en la Constitución tendrá efectos exclusivamente dentro del ámbito de la materia regulada en él. Indudablemente este concepto de bloque de constitucionalidad ha generado grandes disyuntivas en el plano de la doctrina constitucional y procesal constitucional es así como el Doctor Manuel Fernando quinche Ramírez define la figura del bloque de constitucionalidad como las normas internacionales, en el ejercicio del control de 
constitucionalidad. Como metáfora y como concepto, permite comprender que la Constitución colombiana no se agota en los 380 artículos de su texto, sino que abarca otros componentes, preferentemente de Derecho Internacional, que son también normas constitucionales (Quinche, 2009 , p.169). Este bloque de constitucional surge como el mecanismo por excelencia que garantiza la teoría dela internacionalización del derecho constitucional, entendida esta como la aplicación de normas internacionales dentro del derecho interno de cada estado, en Colombia la figura del bloque de constitucionalidad es entendida en dos sentidos que abordaremos con posterioridad en nuestro estudio, se debe enfatizar en que la función principal de este mecanismo es lograr proteger de manera eficaz, efectiva los derechos de las personas asociadas a un estado.

Como lo dijimos anteriormente esta figura de bloque de constitucionalidad es asimilada desde dos perspectivas que son desarrolladas o entendidas en sentido amplio y en sentido estricto, tal como lo define la corte constitucional en la sentencia C-200 DE 2002 (Corte Constitucional C200 de 2002. M.P. Álvaro Tafur Galvis), ahora bien, en ese primer sentido la corte constitucional establece que existe un ensanchamiento de la constitución política y que esta no se agota con los artículos que esta contiene, sino que se remite a disposiciones de carácter internacional, en sentido estricto se refiere meramente a las disposiciones contenidas en los tratados internacionales que hacen parte del grueso interpretativo que deben tener en cuenta los jueces para tomar determinada decisión.

Lo anterior es una muestra clara de cómo los Estados crean estrategias para proteger y otorgar garantías a las personas sujetas a su jurisdicción, entendiendo que los tiempos cambiantes te obligan adoptar medidas acordes a la realidad para cumplir con los presupuestos de un Estado Social de Derecho, el bloque de constitucionalidad es una figura que invita a los estados a garantizar de manera activa y siempre de forma progresiva los derechos humanos para esto desarrollo y afirmación de principios trascienden circunstancias en concreto y se van constituyendo en referentes fundamentales no sólo en la jurisprudencia nacional sino, en perspectiva, en la organización interna de los Estados y en el diseño y ejecución de sus normas jurídicas.

Cabe aclarar, que los garantes de los derechos humanos lo fueron siempre los jueces en primera línea, pero en ocasiones en un sentido meramente formal. Al acercarse a estándares internacionales y a criterios sustantivos que ponen por delante los derechos de la gente, los sistemas judiciales nacionales dinamizan y legitiman su papel en el continente americano resulta indispensable a unir esfuerzos por un objetivo común, el de la creación de un ius comune interamericano, en procura de tal final es indispensable un eventual código procesal convencional puede hacer parte del ordenamiento jurídico de cada Estado, es decir representa el lugar que va 
ocupar dicho código, debido a que no lo encontraremos de manera formal, en cada constitución de dicho Estado, pero será integrante del cuerpo normativo de dicho ente Estatal.

\section{Necesidad de aplicabilidad de estándares procesales claros.}

Una de las iniciativas a impulsar desde la ciencia derecho procesal constitucional y en relación a la codificación procesal constitucional, es el cumplimiento de los Estados entorno a las obligaciones que se derivan del derecho internacional representadas en Obligaciones de Respeto y Obligaciones de Garantía, entendida la primera, como el deber que tienen los Estados de abstenerse de ejecutar acciones que pueda afectar los derechos de las personas, la obligación de garantía es el deber de los Estados de adecuar su legislación interna de tal manera que sea capaz de asegurar el libre y pleno ejercicio de los derechos reconocidos en la convención (Medina, Felipe, s.f. p. 12).

Sin lugar a duda la idea de una codificación procesal convencional se circunscribe a las obligaciones que mencionamos anteriormente y que se encuentran en cabeza del Estado, debido a que nos encontramos ante las reglas que deben ser adoptadas para determinar el procedimiento de los sujetos en el marco de acción de la jurisdicción de cada Estado y del sistema interamericano, es decir se cimentan las reglas básicas para la materialización de dichos derechos que tanto hacemos remisión en los tratados internacionales y las constituciones locales.

Vale la pena indicar que con una codificación procesal convencional lo que se busca es que el derecho procesal de los derechos humanos realmente responda al objetivo principal que es garantizar la aplicación de unas líneas procedimentales que permitan un efectivo acceso y aplicabilidad de los postulados del sistema interamericano.

Bajo esa condición es menester precisar que la máxima expresión del respeto a los derechos humanos del hombre es a través de la aplicación efectiva de los derechos reconocidos en los tratados de derechos humanos, la corte interamericana ha sido pionera en la región en cuanto en a la protección de los derechos de las personas una de las formas que se ha ingeniado es el valor que ha adquirido las decisiones que este toma entorno a las presuntas violaciones de derechos humanos, el cual ha sido denominado como control de convencionalidad, que fue abordado primeramente en el fallo del caso Almonacid Arellano vs. Chile (Corte IDH. Caso Almonacid Arellanos vs Chile), donde se establecieron los elementos que componen la figura del control de convencionalidad, dentro de las cuales encontramos, a) Consiste en verificar la compatibilidad de las normas y demás prácticas internas con la $\mathrm{CADH}$, la jurisprudencia de la Corte IDH y los demás tratados interamericanos de los cuales el Estado sea parte; b) Es una obligación que corresponde a toda autoridad pública en el ámbito de sus competencias; c) Para efectos de determinar la compatibilidad con la $\mathrm{CADH}$, no sólo se debe tomar en consideración el 
tratado, sino que también la jurisprudencia de la Corte IDH y los demás tratados interamericanos de los cuales el Estado sea parte; d) Es un control que debe ser realizado ex oficio por toda autoridad pública; y e) Su ejecución puede implicar la supresión de normas contrarias a la CADH o bien su interpretación conforme a la $\mathrm{CADH}$, dependiendo de las facultades de cada autoridad pública (Cuadernillo de Jurisprudencia de la Corte Interamericana de Derechos Humanos № 7. Control de Convencionalidad. p. 6.) (Obtenido en: http://www.corteidh.or.cr/tablas/r33825.pdf), es decir se refiere a la integralidad de las disposiciones nacionales como internacionales, para ofrecer una más amplia protección de derechos, el trabajo armónico de estos dos sistemas, determina que los jueces también están sometidos a ella, lo que les obliga a velar porque el efecto útil de la Convención no se vea mermado o anulado por la aplicación de leyes contrarias a sus disposiciones, objeto y fin. En otras palabras, los órganos del Poder Judicial deben ejercer no sólo un control de constitucionalidad, sino también "de convencionalidad" ex oficio entre las normas internas y la Convención Americana, evidentemente en el marco de sus respectivas competencias y de las regulaciones procesales correspondientes.

Bajo lo antes expuesto y bajo el caso concreto del estado colombiano que aborda un periodo de justicia transicional Y Bajo La Amenaza De Una Politización del proceso de implementación actual acuerdo de paz, ante las posibles intenciones de sectores políticos de establecer acciones tendientes al desconocimiento del acuerdo generando escenarios que imposibilitarían el derecho "la total indefensión de las víctimas y de sus familiares, quienes tienen derecho a conocer la verdad de los hechos" (Anzualdo Castro vs. Perú, 2009) Generando con total seguridad una serie de casos de responsabilidad internacional del estado colombiano, entonces ante problemáticas de orden similar que puedan acarrear las decisiones políticas, en la práctica de gobierno de los Estados comúnmente activa la competencia de la corte, ya sea en disposiciones consultivas o en la solución de casos contenciosos en los que comúnmente se condenan a los estados.

\section{Excepciones preliminares un espejismo de derecho a la defensa.}

La corte interamericana de derechos humanos nace bajo la necesidad de un sistema regional de promoción y protección de los derechos humanos, al reconocer estos derechos, establecer obligaciones tendientes a su promoción y protección, y crear órganos destinados a velar por su observancia, en este sistema que consta de una notable inclinación pro victima encontramos las excepciones entendiendo que por "excepción preliminar", en su jurisprudencia la Corte ha afirmado reiteradamente que por este medio se cuestiona la admisibilidad de una demanda o la competencia del Tribunal para conocer determinado caso o alguno de sus aspectos, en razón de la persona, la materia, el tiempo o el lugar ( Caso Las Palmeras Vs. Colombia. , 2000. ) en estas excepciones que tienen procedencia al interior del procedimiento judicial para determinar la responsabilidad internacional de los Estados convencionalizados se han desarrollado prácticas y realizado modificaciones en relación con el trámite de las distintas etapas a procesales, con el fin 
de ponderar el cumplimiento de las obligaciones de la Convención por parte de los Estados, esto en procura de otorgar cuando menos un equilibrio procesal entre el proceso de declaración de responsabilidad del estado.

Estas excepciones, ya sean a la competencia de la corte “... "o a la calidad de las partes" tienen una procedencia casi nula, siendo muy pocos los casos en los que han prosperado, como ejemplo está el caso Alfonso Martín del Campo Dodd Vs. Estados Unidos Mexicanos en el que la corte ordenó 1) Acoger la primera excepción preliminar ratione temporis interpuesta por el Estado, en los términos de los párrafos 78 a 85 de la presente Sentencia. 2. Archivar el expediente. 3. Notificar la presente Sentencia al Estado, a la Comisión Interamericana de Derechos Humanos y a los representantes de la presunta víctima y sus familiares. Bajo el argumento antes mencionado y en otros casos ha sostenido interpretaciones de notoria extensividad que resultan esfuerzos más que notables en la garantía de los derechos humanos, pero generan una sensación de desbalance pronunciado en las armas procesales del sistema.

Casos como el Caso Masacre de Santo Domingo Vs. Colombia, de 30 de noviembre, que en su párrafo 211 manifiesta que la corte analizará los hechos del caso interpretando las disposiciones de la Convención Americana a la luz de las normas y principios pertinentes del derecho internacional humanitario, conociendo entonces aspectos que van más allá de sus competencias naturales; casos como estos resultan cuando menos inquietantes, pues los Estados que parten de unas reglas procesales preestablecidas por la normatividad americana, se encuentran cada día inmersos en el espectro de una competencia de la Corte, que parece crecer de manera notable pudiendo ocasionar la necesidad de los Estados de revisar su permanencia en el Sistema al considerar amenazante las acciones del mismo ante principios como la libre configuración legislativa y la libre autodeterminación de los pueblos pues la Corte ha estimado que la necesidad de la protección, promoción y garantía a los derechos humanos constituye un límite infranqueable a regla de mayorías, En las instancias democráticas donde las mayorías; a la regla de mayorías, pueden decidir, la protección de los derechos humanos constituye un límite infranqueable a la regla de mayorías (Caso Gelman Vs. Uruguay, 2011.) Ordenando así la exclusión de una normatividad vigente.

\section{CONCLUSIÓN}

La dinámica a la que debe enfrentarse el derecho procesal constitucional implica la integración pronta y efectiva de asuntos de complejos trascendentales e interdependientes como el derecho multinivel, los diálogos interjurisdiccionales (Tribunales Internacionales) que cristalice los anhelos de la tutela judicial efectiva de los arbotantes jurídicos nacionales e internacionales, permitiendo así la aplicabilidad efectiva de la Convención Americana de derechos y humanos como cuerpo normativo y la sustancia de la misma traducido en derecho y prerrogativas o garantías del 
individuo en cada sociedad, encaminados a la conformación de un verdadero ius comune interamericano; estos retos que se hacen vigente, hoy más que nunca deben valorarse los esfuerzos que se puedan hacer para construir sistemas jurídicos capaces de adaptarse de manera fiel, a la realidad regional, los que deben responder a los anhelos de justicia de sus coasociados; justicia representada en el poder judicial, que se encarga de regular y vigilar el cumplimiento de los mandatos normativos, que no pueden ser considerados como de solo expectativas o de simple aspiraciones que debieran acatarse. Si no como necesidades constantes que nacen como derecho de los asociados y no en calidad de beneficencia partiendo del hecho de que desde la conformación jurídica y política de la sociedad llamada estado, se imponen obligaciones y deberes también tiene la máxima responsabilidad de proveernos y garantizar.

Es por ello que no podemos entonces desconocer el papel que juegan los operadores estatales en todos sus niveles (referencias casos Almonacid Arellanos y otros vs chile, y Gelman vs Uruguay) $y$ en particular los operadores judiciales como aquellos garantes (alfiles abanderados tamborileros) encargados de materializar la justica, de hacer la declaración del derecho, acto de responsabilidad humano-Estado-Sociedad, que refleja la administración de justicia, y que da la impronta para que, entre otros, y nosotros como estudiantes de esta apasionante ciencia nos embargue el concepto de balanza, equidad, igualdad a la que están obligados a cumplir, labor para nada sencilla de ejecutar, y más aún en tiempos de post-acuerdo, en tiempos de la postverdad; sin embargo no todo es desalentador, toda vez que los jueces cuentan con los instrumentos necesarios para dar respuesta a esas responsabilidades; casos como el de Catalán en el que un juez de una comunidad del Estado alemán, como ha sido catalogado por muchos juristas y medios en España, puso en la discusión europea si podía considerarse o no rebelión lo sucedido en esa comarca, con las lamentables consecuencias para la democracia española. Son estos casos en los que se ven encontradas las pretensiones del Estado y miembros de la comunidad, pese a las tensiones y problemas jurídicos que se puedan derivar; esa es la finalidad de este esfuerzo humano delegado en el Estado, y de hecho, en los administradores de justicia, resolver las problemáticas que se presentan como resultado de la natural interacción de los seres humanos en las sociedades que en tiempos modernos en los que como de costumbre debemos recurrir a los clásicos como Chioevenda, Carnelutti, Kelsen entre otros, para que todos los que conformamos a esta comunidad jurídica redefinamos las razones fundamentales que mueven a esta ciencia, este arte, y noble profesión, que no pretende más que ser el instrumento que permite la materialización de la justicia, como ese único valor que puede cimentar las bases necesarias para la materialización de un real Estado social y democrático de derecho. 
Dudley Duque Sierra, Luis Alberto Rivas Mosquera, Andrés Francisco Mena Romaña

\section{REFERENCIAS BIBLIOGRÁFICAS}

PRIETO sanchiz, L. Teoría del Derecho y Filosofía Política en Ronald Dworkin. Pág. 354. Obtenido en: file:///C:/Users/usuario1/Downloads/DialnetTeoriaDelDerechoYFilosofiaPoliticaEnRonaldDworkin241940.pdf

FAVOREU, L. (1994) Los Tribunales Constitucionales. Barcelona: Editorial Ariel.

KELSEN, H. (2009) Teoría Pura del Derecho. Pág. 162. Obtenido:

http://cvperu.typepad.com/files/libro-teoria-pura-del-derecho-hans-kelsen.pdf

FERRER Mac-gregor, (2011) E. Interpretación conforme y control difuso de convencionalidad. El nuevo paradigma para el juez mexicano Estudios Constitucionales vol. 9, núm. 2, pp. 531-622 Centro de Estudios Constitucionales de Chile Santiago, Chile. Disponible en:

http://www.redalyc.org/articulo.oa?id=82022776013. Consultado el 18 de abril de 2015

SANTIAGO, A. Neoconstitucionalismo. Pág. 3. Obtenido en:

https://ancmyp.org.ar/user/files/02neoconstitucionalismo.pdf

GARCÍA ramírez, S. (2014) Breves consideraciones sobre el diálogo jurisprudencial y el control de convencionalidad en el sistema interamericano XXXIV congreso colombiano de derecho procesal; primera edición.

SANTIAGO, alfonso. (2008) Neoconstitucionalismo. Pág. 5, 6. Obtenido en: https://ancmyp.org.ar/user/files/02neoconstitucionalismo.pdf

KALACH, G. (2016). Las comisiones de la verdad en Colombia (2016) Revista Jurídica Mario Alario D'Filippo. VIII, (16): 106-124. Recuperado de DOI: https://doi.org/10.32997/2256-2796- vol.8num.16-2016-1534

COLOMBO, campbell, juan. (2002) Funciones del Derecho Procesal Constitucional. Pág. 137. Obtenido en: https://revistas-colaboracion.juridicas.unam.mx/index.php/anuario-derechoconstitucional/article/viewFile/3555/3322

FERRER mac-gregor, eduardo, (s.f) Héctor Fix-Zamudio y el origen científico del derecho procesal constitucional (1928-1956). En: Ferrer Mac-Gregor, Eduardo, Zaldívar lelo de Larrea, Arturo (coords), Estudios en Homenaje a Héctor Fix-Zamudio en sus cincuenta años como investigador del derecho .Tomo 1. 
INSTITUTO DE INVESTIGACIONES (2008) Jurídicas Teoría general del derecho procesal constitucional, México, UNAM, IMDPC, marcial pons. pp. 589 y 599, Serie Doctrina Jurídica, no.436

CORRADO de paz, m. Codificación del derecho procesal constitucional, P. 284- 287

QUINCHE Ramírez, m. (2009) Control de convencionalidad y sistema colombiano. Pg. 169. Obtenido en http://www.corteidh.or.cr/tablas/r25586.pdf

MEDINA, F. (s.f) Responsabilidad Internacional del Estado por actos de particulares. Pág. 12. Obtenedlo en: http://www.corteidh.or.cr/tablas/r26724.pdf

TIRADO Pertúz, César Andrés; luna salas, Fernando (2015). La creación pretoriana del Derecho Procesal Constitucional en la Acción de Tutela. Revista Jurídica Mario Alario D’Filippo, VII (14), pág 22-40:

http://revistas.unicartagena.edu.co/index.php/marioalariodfilippo/article/view/268

\section{Jurisprudencia}

En las sentencias de los casos Almonacid Arellanos y otros vs chile, y Gelman vs Uruguay. Ver Juan Carlos Hitters, Control de constitucionalidad y control de convencionalidad. Comparación (Criterios fijados por la Corte Interamericana de Derechos Humanos), 7(2) ESTUDIOS CONSTITUCIONALES 109, 113-14 (2009).

Corte Constitucional C200 de 2002. M.P. Álvaro Tafur Galvis. 